\section{Mini-Review}

Correspondence

Tim J. Mitchell

t.mitchell@bio.gla.ac.uk

\title{
Innate immunity and the pneumococcus
}

\author{
Gavin K. Paterson and Tim J. Mitchell \\ Division of Infection and Immunity, University of Glasgow, Glasgow G12 800, UK
}

\begin{abstract}
The innate immune system provides a non-specific first line of defence against microbes and is crucial both in the development and effector stages of subsequent adaptive immune responses. Consistent with its importance, study of the innate immune system is a broad and fast-moving field. Here we provide an overview of the recent key advances made in this area with relation to the important pathogen Streptococcus pneumoniae (the pneumococcus).
\end{abstract}

\section{Introduction}

Innate immunity covers a diverse array of host defences, including mucociliary clearance, complement, neutrophils and macrophages. It acts as a non-specific defence able to recognize and respond rapidly against a broad range of microbes. Unlike adaptive immunity, which involves the clonal expansion of $\mathrm{T}$ and $\mathrm{B}$ cells specific to the pathogen, innate recognition is achieved through a limited set of germline-encoded receptors and does not possess immunological memory. The two systems do not however operate in isolation, as the innate immune system plays crucial roles in the initiation, development and effector stages of adaptive immunity. Recent advances in innate immune recognition and response to the pneumococcus (Streptococcus pneumoniae) are discussed here. Better understanding of these interactions may ultimately aid therapy through the promotion of protective responses and the inhibition of deleterious ones.

\section{Complement and the pneumococcus}

The complement system comprises over 30 serum and membrane proteins which, when activated, form a cascade of reactions contributing to the elimination of invading microorganisms. The binding and activation of complement components to the surface of a microbe leads to opsonophagocytosis and the induction of inflammation. For some organisms, but not the pneumococcus, complement can destroy the microbe directly through lysis by the membrane attack complex. Complement contributes to and links both innate and adaptive immunity. Three pathways of activation exist (reviewed by Walport, 2001); in brief, these are:

1) The classical pathway activated by antibody-antigen complexes; for example, antibody binding to the microbial surface. Non-antibody-dependent activation can also occur, such as the binding of acute-phase proteins to the micro-organism.

2) The lectin pathway, which is triggered by mannosebinding lectin recognition of carbohydrate on the microbial surface.
3) The alternative pathway, which is continuously activated at low levels, but only amplifies on foreign surfaces.

The crucial contribution of complement to innate and adaptive responses to pneumococcal infection is long established, both in animal models and in humans with genetic complement deficiencies (for recent overview see Hostetter, 2004). However, only recently, through the use of a panel of gene knock-out mice lacking various complement components, has the relative importance of individual activation pathways been assessed in innate immunity to pneumococcal infection (Brown et al., 2002). The classical pathway of complement activation has been found to be the dominant complement pathway for innate immunity to the pneumococcus in mice (Brown et al., 2002), the specific loss of which results in significantly increased disease severity. Natural IgM antibodies, possibly to $\mathrm{C}$ polysaccharide (teichoic acid), contribute to this activation of the classical pathway, as shown by the use of $\mu_{\mathrm{S}}^{-/-}$knock-out mice which lack such antibodies (Brown et al., 2002). However, the activation of the classical pathway during this innate immune response is only partially dependent on natural antibodies, and other activation pathways also contribute. These are proposed to include acute-phase proteins, such as C-reactive protein, or direct binding of complement component C1q to the pneumococcal surface (Brown et al., 2002). The alternative pathway also contributes to protective innate responses, but to a lesser degree than seen for the classical pathway, while the role for the lectin pathway appears negligible. In line with this latter finding, genetic mannose-binding lectin deficiency is associated with only a small (but significant) increased susceptibility to pneumococcal disease in humans (Roy et al., 2002). Regardless of the activation pathway, the deposition and activation of complement component $\mathrm{C} 3$ on the bacterial surface is a key step in the complement cascade leading to elimination of the microbe. In accordance with this crucial role of complement in innate immunity, the pneumococcus has evolved several mechanisms to resist its effects. The capsule is a key factor in this resistance, not only acting to limit access to cell-bound complement but also reducing the amount of complement 
deposited (Abeyta et al., 2003). The pneumococcal surface protein PhpA [also called PhtB and BVH-11 (Hamel et al., 2004)] has been found to possess C3-degrading activity (Angel et al., 1994; Zhang et al., 2001), and so PhpA may contribute to the prevention of complement-mediated clearance. In addition to its cytolytic activity, the toxin pneumolysin, a major pneumococcal virulence factor, has multiple other biological activities (for review see Mitchell, 2004). Recently, pneumolysin has been shown to confer protection from complement-mediated clearance (Yuste et al., 2005). Deletion of pneumolysin causes an increase in C3 deposition on pneumococcal cells in vitro. Showing that this activity of pneumolysin contributes to virulence, absence of complement in gene knock-out mice reduces the importance of pneumolysin to pneumococcal virulence. Furthermore, this effect of pneumolysin in vitro and in vivo is specific to the classical and not the alternative activation pathway (Yuste et al., 2005). The mechanisms by which pneumolysin achieves this effect are as yet unconfirmed. However, this specific evasion of the classical pathway is in agreement with the ability of pneumolysin to activate this pathway in the absence of specific toxin antibodies (Mitchell et al., 1991; Paton et al., 1984). Thus, complement evasion in this instance may ironically be the result of complement activation rather than inhibition. Released pneumolysin may result in complement activation away from the bacterial cell, thus protecting it and also consuming the available complement components. In addition, increased complement activation may contribute to host-tissue damage, thereby promoting bacterial pathogenesis. Furthermore, the surface proteins PspA and PspC also contribute to complement resistance, but these proteins are covered in a companion review in this issue (Bergmann \& Hammerschmidt, 2006).

\section{Pattern recognition receptors}

Key components of the innate immune system are socalled pathogen recognition receptors (PRRs). These can be located on the host cell surface, intracellularly or be secreted and act to initiate the recognition of and response to microbes and in some cases host products (Janeway \& Medzhitov, 2002). The microbial components recognized by PRRs are referred to as pathogen-associated molecular patterns (PAMPs), so-called because they are typically invariant structures found among many microbes but absent in eukaryotes. The use of the term pathogen is potentially misleading, as many PAMPs are conserved among both pathogens and non-pathogens. Examples include lipopolysaccharide (LPS) and peptidoglycan from bacteria, doublestranded RNA from certain viruses and mannan from fungi. C-reactive protein (CRP) is a well-known example of a PRR involved in the response to the pneumococcus. This soluble protein binds phosphorylcholine in the pneumococcal cell wall, inducing complement activation and leading to bacterial clearance (Mold et al., 2002; Szalai et al., 1997). Additional PRRs important in pneumococcal infection have recently been described, including members of the toll-like receptor (TLR) family, discussed below. The key PRRs discussed in this review are shown in Fig. 1.

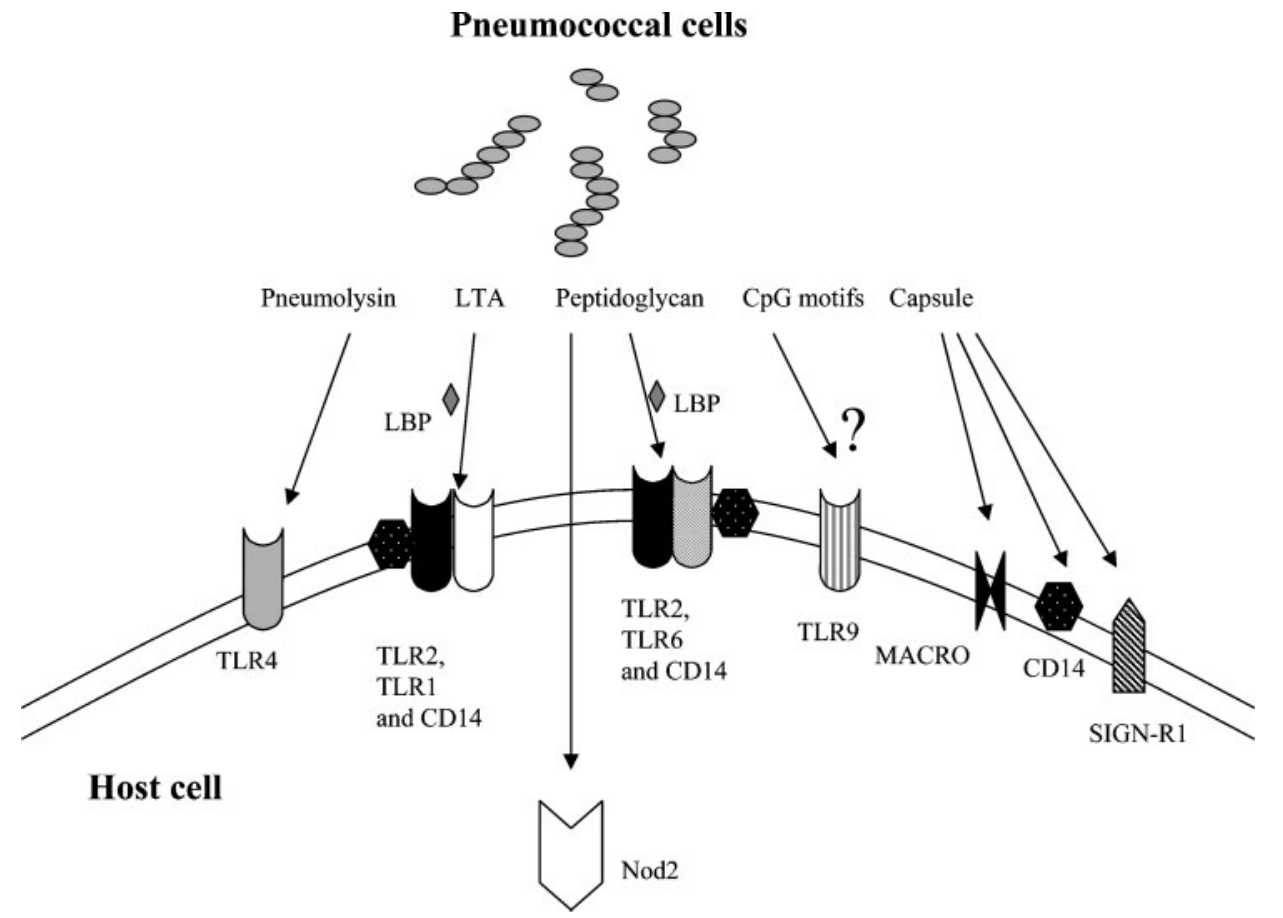

Fig. 1. Key pathogen recognition receptors involved in the recognition and initiation of the immune response towards the pneumococcus. Abbreviations: LBP, LPS binding protein; LTA, lipoteichoic acid; TLR, toll-like receptor. 


\section{Toll-like receptors}

The TLR family of PRRs has received much attention due to their importance in the response to a wide range of microbes (for reviews see Hopkins \& Sriskandan, 2005; Takeda et al., 2003). Their major function as PRRs is to recognize microbes and initiate an inflammatory response leading to eradication of infection. At least ten TLRs have been described in humans and mice, and several have been implicated in pneumococcal infection in animal models. Furthermore, descriptions of genetic defects in TLR signalling associated with increased susceptibility to pneumococcal disease show that these receptors have relevance to human infection (Currie et al., 2004; Picard et al., 2003).

TLR2. TLR2 recognizes both pneumococcal lipoteichoic acid (LTA) and cell wall peptidoglycan (Han et al., 2003; Schroder et al., 2003; Weber et al., 2003; Yoshimura et al., 1999). Interestingly, despite numerous studies supporting the recognition of bacterial peptidoglycan via TLR2, this interaction has recently been challenged (Travassos et al., 2004). Echchannaoui et al. (2002) show that TLR2 ${ }^{-1-}$ mice display increased disease severity and decreased survival times compared with wild-type mice in a pneumococcal meningitis model. This greater susceptibility correlates with heightened bacterial levels in the brain but appears to be independent of systemic disease, as both strains show similar bacterial levels in the blood. A transient delay in leukocyte recruitment into the brain potentially contributes to increased bacterial outgrowth and disease progression in the knock-out mice. Despite this slower early leukocyte recruitment, knock-out mice show enhanced inflammation in the brain later in infection. This is perhaps due to the increased bacterial levels providing a greater inflammatory stimulus, which may in turn contribute to increased disease through immunopathology.

In agreement with these data, Koedel et al. (2003) have also found in their meningitis model that TLR2 ${ }^{-1-}$ mice have enhanced disease and increased bacterial levels in the brain.

The role of TLR2 has also been investigated in experimental pneumococcal pneumonia (Knapp et al., 2004). Comparison between wild-type and TLR2 ${ }^{-1-}$ mice following intranasal infection reveals only a modest contribution for this receptor in the host response. Although TLR2 knockout mice show reduced pulmonary inflammation, no difference is seen with regard to bacterial clearance and morbidity compared with their wild-type counterparts. On the basis of these data, TLR2 does not appear to play a key role in host resistance to pneumococcal pneumonia. Interestingly, the stimulation of isolated alveolar macrophages in vitro to produce TNF- $\alpha$ in response to heat-killed pneumococci is entirely dependent on TLR2 (Knapp et al., 2004). However, immunohistochemical staining of infected lungs from $\mathrm{TLR}^{-1-}$ mice shows that these cells are producing TNF$\alpha$ at a level comparable to that of wild-type mice. Presumably in the setting of the intact animal, other host innate immune factors, such as other PRRs and complement, mask the loss of TLR2, rendering its influence minimal in pneumococcal pneumonia. It is clear that the complexity of the immune response, with numerous interacting factors, makes the use of intact animal models an essential tool.

Following intraperitoneal infection, TLR2 knock-out mice have slightly reduced survival times compared with wildtype (Khan et al., 2005). Thus, TLR2 has a protective role in this model of systemic infection, although as with pneumonia, the defect is arguably minor.

Furthermore, in a model of nasopharyngeal colonization, TLR2 knock-out mice have impaired clearance of pneumococci (van Rossum et al., 2005), showing that TLR2 is of relevance not only to disease states but also carriage.

TLR4. Through the recognition of LPS, TLR4 is a key component of the innate response to Gram-negative infections. A role for this receptor has also been extended to the pneumococcus with the finding that the in vitro proinflammatory affect of pneumolysin on macrophages is TLR4 dependent (Malley et al., 2003). Subsequently, pneumolysin has been shown to directly interact with TLR4 (Srivastava et al., 2005). This inflammatory activity is not dependent on the pore-forming or complement-activating activities of pneumolysin because the PdT pneumolysin mutant, which lacks these properties, was also active. The significance of this interaction during colonization has been studied by comparing wild-type and TLR4-deficient mice in a nasopharyngeal carriage model (Malley et al., 2003). In the absence of functional TLR4, mice are more heavily colonized and much more likely to develop invasive disease. Thus, through its recognition of pneumolysin, TLR4 acts in the nasopharynx to limit pneumococcal proliferation. While the inflammatory response to pneumolysin may contribute to this protection, it has also been shown that pneumolysin-TLR4 signalling can induce hostcell apoptosis in vitro and in vivo (Srivastava et al., 2005). This also appears to be a protective host response, as the inhibition of apoptosis renders mice more susceptible to death following pneumococcal infection (Srivastava et al., 2005). Interestingly, a similar model of colonization using the same mouse strains has found no difference in the clearance of pneumococci between wild-type and TLR4deficient mice (van Rossum et al., 2005). The use of different bacterial strains in these studies may explain this apparent conflict, but this remains to be tested. In pneumococcal pneumonia, TLR4 also plays a protective role (Branger et al., 2004b). In this experimental model, the absence of functional TLR4 renders mice more susceptible to morbidity with increased bacterial counts in the lungs. The effects, however, are modest, with the effect on death rate only apparent at low doses and with no significant impact on pulmonary inflammation. Furthermore, the significance of TLR4 in pneumococcal infections appears restricted to the airway surfaces, as earlier work has found that the absence of TLR4 makes no difference 
to survival rates and blood bacterial counts after intravenous infection of mice (Benton et al., 1997).

TLR9. Bacterial DNA has inflammatory properties resulting from the presence of unmethylated cytosine-phosphateguanosine (CpG) motifs (for review see Krieg, 2002). Unmethylated $\mathrm{CpG}$ motifs are therefore an additional PAMP and have been shown to be recognized by and to confer their activity via TLR9 (Bauer et al., 2001). The autolytic nature of the pneumococcus with resultant DNA release (Moscoso \& Claverys, 2004) may make the interaction between bacterial DNA and TLR9 important during pneumococcal infection. This supposition is untested, and it would be of interest to investigate the response to pneumococcal infection in TLR9-deficient mice. Interestingly, the transfection of HEK293 cells with TLR9 fails to confer responsiveness to the pneumococcus, whereas TLR2 and TLR 4 do (Koedel et al., 2003). Therefore the role of TLR9 in pneumococcal infections remains to be confirmed.

TLR1 and TLR6. The recognition of pneumococcal peptidoglycan probably involves interaction between TLR2 and TLR6, as shown for Staphylococcus aureus peptidoglycan (Ozinsky et al., 2000). Indeed, confirming a role for this receptor in pneumococcal recognition, the expression of a double negative TLR6 mutant inhibits TNF- $\alpha$ production in response to stimulation by the pneumococcus in a macrophage cell line (Ozinsky et al., 2000). A role exists for TLR1 in the recognition of pneumococcal LTA, whereby monoclonal antibodies against this receptor inhibit LTAinduced TNF- $\alpha$ production from human peripheral blood mononuclear cells (Han et al., 2003). The importance of these interactions between the pneumococcus and TLR1 and TLR6 has not yet been assessed in an infection model.

TLR signalling. Myeloid differentiation factor 88 (MyD88) is a key adaptor molecule in the signalling cascade activated by engagement of TLRs or interleukin-1 (IL-1) family receptors (Yamamoto et al., 2004). In agreement with a role for TLRs in innate protection against pneumococcal infection, ${\mathrm{MyD} 88^{-1-}}$ mice show enhanced susceptibility to S. pneumoniae in different infection models (Albiger et al., 2005; Khan et al., 2005; Koedel et al., 2004). Providing relevance to human infection, deficiency in IL-1 receptorassociated kinase 4 (IRAK4), also a mediator in the TLR/ IL-1 receptor signalling pathway, results in increased susceptibility to pneumococcal disease (Picard et al., 2003), as does a distinct, but as yet undefined, mutation in this signalling pathway (Currie et al., 2004).

\section{LPS binding protein (LBP)}

In addition to TLR2, the pneumococcal cell wall (PCW) is recognized by the soluble acute-phase protein LBP (Weber et al., 2003). This protein has previously been found to bind LPS and enhance its inflammatory activity. It has now also been found to bind purified PCW and whole pneumococci, and the addition of LBP accentuates the inflammatory activity of PCW in vitro (Weber et al., 2003). This has been extended to a mouse meningitis model, in which LBP gene knock-out mice show significantly reduced meningeal inflammation following challenge with purified cell wall or live pneumococci. Clinical outcome was not assessed, but in this setting it might be predicted that the absence of LBP would be beneficial. Recognition of PCW by LBP appears independent of cell wall phosphorylcholine and teichoic acid, with the glycan backbone seemingly a crucial structure for this interaction (Weber et al., 2003). Significance to human infections is shown by enhanced LBP levels in the cerebrospinal fluid (CSF) of pneumococcal patients compared with controls. Furthermore, PCW coprecipated with LBP in the CSF from a patient, showing that this interaction occurs in human infection (Weber et al., 2003). LBP also contributes to the response to pneumococcal LTA (Schroder et al., 2003). However, LBP gene knock-out mice do not have altered susceptibility or responses to pneumococcal pneumonia (Branger et al., 2004a). Given that LBP acts to facilitate recognition of TLR2 ligands, this phenotype is compatible with the modest effect seen with TLR2 knockout mice in similar infections (Knapp et al., 2004). Interestingly, LBP levels in lavage fluid increase sevenfold during experimental pneumococcal infection (Branger et al., 2004a). This is a much greater increase than that seen with parallel Klebsiella pneumoniae pneumonia (Branger et al., 2004a). However, endogenous LBP contributes significantly to protection against $K$. pneumoniae pneumonia, which is not the case for pneumococcal pneumonia (Branger et al., 2004a). Clearly, this highlights that functional importance cannot easily be predicted from expression levels alone.

\section{CD14}

Membrane-bound and soluble CD14 acts as a co-receptor to enhance the response to LPS (Abeyta et al., 2003; Pugin et al., 1993, 1994). CD14 also contributes to the recognition of the pneumococcus in vitro (Cauwels et al., 1997; Han et al., 2003; Schroder et al., 2003; Yoshimura et al., 1999). A role in infection has also been confirmed by the recent finding that CD14 gene knock-out mice show exacerbated pneumococcal meningitis (Echchannaoui et al., 2005).

\section{Nod proteins and the pneumococcus}

The cytosolic proteins Nod 1 and Nod2 are additional PRRs acting within host cells to recognize and respond to microbial products (Philpott \& Girardin, 2004). In addition to TLRs, a role for Nod proteins in the recognition and response to pneumococci has also been shown (Opitz et al., 2004). Transfection with Nod2, but not Nod1, confers responsiveness to cells following pneumococcal exposure, as judged by NF- $\kappa$ B activation (Opitz et al., 2004). In line with the role of Nod proteins in the response to intracellular material, the recognition of pneumococcus by Nod2 is dependent on internalization of the bacteria. Nod2 has previously been shown to be responsive to a muramyldipeptide conserved in multiple peptidoglycans, and this is 
the suggested mechanism for its recognition of the pneumococcus (Opitz et al., 2004). The availability of Nod 1 and Nod2 knockout mice will allow a fuller appreciation of these genes in the host response to the pneumococcus (Chamaillard et al., 2003; Girardin et al., 2003; Pauleau \& Murray, 2003).

\section{Recognition of capsule}

Recognition of the pneumococcal polysaccharide capsule by PRRs has received much attention of late. Kang and coworkers showed that the C-type lectin SIGN-R1 expressed by macrophages, particularly in the marginal zone of the mouse spleen, binds capsular polysaccharide from several different serotypes, as well as whole pneumococcal cells (Kang et al., 2004). Lanoue et al. (2004) have demonstrated a functional significance of this interaction with the generation of SIGN-R1 gene knock-out mice. Following intraperitoneal infection with either serotype 2 or serotype 14 pneumococci, these mice display increased susceptibility to infection compared with their wild-type counterparts. Absence of SIGN-R1 causes a decrease in survival rate, shorter time to death, increased sickness scores and increased bacterial levels in the blood. A defect in the ability of macrophages in the peritoneum and spleen to bind and phagocytose the pneumococcus is likely to be a major contributor to the increased susceptibility of the knock-out mice (Lanoue et al., 2004).

The role of SIGN-R1 in pneumococcal pneumonia has also been investigated with the use of SIGN-R1-deficient mice (Koppel et al., 2005). When infected intranasally with a serotype 3 strain, the SIGN-R1 knock-out mice show increased bacterial levels in the lungs compared with wild-type. This is accompanied by a higher incidence of bacteraemia, and increased bacterial counts in the blood and spleen. Interestingly, alveolar macrophages do not express SIGN-R1, and expression is not induced following pneumococcal infection (Koppel et al., 2005). This suggests that the protective role of SIGN-R1 in pneumonia does not occur within the lungs themselves. One potential mechanism for the increased bacterial growth in the absence of SIGN-R1 is found to be reduced levels of anti-phosphorylcholine IgM. In addition, systemic disease in this model is probably exacerbated by defective phagocytosis by macrophages in the peritoneum and spleen, as described by Lanoue et al. (2004) Therefore, in both pulmonary and systemic infections, SIGN-R1 is instrumental in host resistance to the pneumococcus.

Another macrophage receptor, MARCO, has also recently been identified as important in pneumococcal infection (Arredouani et al., 2004). Genetic deletion of this scavenger receptor renders mice more susceptible to pneumococcal pneumonia, with impaired bacterial clearance from the lungs and increased morbidity (Arredouani et al., 2004). Isolated alveolar macrophages from the knock-out mice are impaired in their ability to bind and phagocytose the pneumococcus in vitro, and this is likely a key factor in the increased susceptibility to infection. Interestingly, reduced phagocytosis is not due solely to reduced bacterial binding, and so a role for MARCO appears to exist not only in binding but in subsequent bacterial uptake. The pneumococcal ligands recognized by MARCO have not yet been identified.

Previously, pneumococcal capsular polysaccharide has been shown to activate macrophages (Um et al., 2000), an activity partially dependent on CD14; whether or not this activity also involves SIGN-R1 and MARCO remains to be determined.

\section{Surfactant proteins}

Pulmonary surfactant is a mixture of lipids and proteins that act to prevent alveoli from collapsing during expiration. In addition, the surfactant proteins (SPs) SP-A and SP-D play a role in innate immunity against a variety of pathogens, acting by binding microbes and promoting their phagocytosis or by modulating immune-cell function (Crouch \& Wright, 2001; Whitsett, 2005). In the case of pneumococcal infection, SP-D knock-out mice show enhanced susceptibility to intranasal infection (Jounblat et al., 2005). SP-A has recently been shown to promote phagocytosis of $S$. pneumoniae by rat and mouse alveolar macrophages in vitro (Kuronuma et al., 2004).

\section{$\mathrm{CD4}^{+} \mathrm{T}$ cells in innate immunity to the pneumococcus}

The function of $\mathrm{CD} 4{ }^{+} \mathrm{T}$ cells in adaptive immunity is well established. Interestingly, they appear also to contribute to early resistance to pneumococcal infection independently of their role in adaptive antigen-specific responses (Kadioglu et al., 2004). Intranasal infection of MHCII knock-out mice, which display a significant decrease in $\mathrm{CD} 4^{+} \mathrm{T}$ cell levels, has revealed a key role for these cells in the early response to pneumococcal pneumonia. These mice display increased susceptibility to infection, as evidenced by increased bacterial counts in the lung and blood compared with their wildtype counterparts. Indeed, the increased susceptibility is so great that it results in $100 \%$ mortality in the knock-out mice by 3 days post-infection, whereas all wild-type mice survive the challenge. In accordance with previous data showing $\mathrm{T}$ cell migration to infected lung tissue in pneumococcal pneumonia (Jounblat et al., 2003; Kadioglu et al., 2000), purified $\mathrm{CD} 4{ }^{+} \mathrm{T}$ cells migrate to the pneumococcus in vitro. This migration is associated with $\mathrm{T}$ cell activation, and interestingly occurs only in response to in vivo and not to in vitro grown bacteria. Pneumolysin plays a significant part in this migration, as pneumolysin-deficient pneumococci stimulate significantly less cell migration. How pneumolysin stimulates these $\mathrm{T}$ cells is unclear, but the recent description of TLR4 expression by T cells may be of relevance (KomaiKoma et al., 2004). Recently, Malley et al. (2005) have demonstrated a crucial role for $\mathrm{CD} 4^{+} \mathrm{T}$ cells in antibodyindependent acquired immunity to pneumococcal colonization. How $\mathrm{CD} 4^{+} \mathrm{T}$ cell migration and activation in response to the pneumococcus, as described in pneumonia, 
relates to this acquired immunity to colonization is as yet unclear.

\section{Innate immunity and interaction between the pneumococcus and other microbes}

For ease of study, most work on the interaction of the pneumococcus with the innate immune system has employed pure cultures. However, the mucosa of the upper respiratory tract is colonized by a diverse array of microbial species. Indeed, analysis of DNA from human airway surface fluid suggests the presence of more than 500 bacterial species (Paster et al., 2001). Concurrent stimulation of the innate immune system by multiple species appears to have effects distinct from those of single-species interactions (Neish et al., 2000; Tong et al., 2003), and this has recently been shown to have relevance to the pneumococcus (Ratner et al., 2005). Co-stimulation of human respiratory epithelia cells in vitro by $S$. pneumoniae and Haemophilus influenzae, also an inhabitant of the upper respiratory tract, results in synergistic production of IL-8 (Ratner et al., 2005). This has been extended to a mouse-colonization model, with a synergistic effect on MIP-2 production and inflammatory influx into the upper airways. This synergy is independent of TLR2 and TLR4, but involves NF- $\kappa$ B translocation to the nucleus and phosphorylation of $\mathrm{p} 38$ MAPK. With regard to the microbial products involved, pneumolysin can substitute for the pneumococcus, but the $\mathrm{PdB}$ pneumolysin toxoid, lacking cytolytic activity, is inactive. It is therefore speculated that the pore-forming activity of pneumolysin leads to enhanced delivery of microbial products, such as the soluble inflammatory protein SCF from $\mathrm{H}$. influenzae, into the host cell, where recognition by Nod1 and Nod 2 would result in increased stimulation (Ratner et al., 2005). This proinflammatory activity of pneumolysin is therefore distinct from its effects on macrophages that are mediated through TLR4 and are independent of pore-forming activity.

The significance of pneumococcal- $H$. influenzae interactions has recently been examined in a co-colonization mouse model (Lysenko et al., 2005). In contrast to what might be expected based on in vitro studies with these bacteria (Pericone et al., 2000; Shakhnovich et al., 2002), cocolonization in vivo results in rapid clearance of the pneumococcus. This effect is dependent on the innate immune system in the form of neutrophils and complement, with the depletion of either abolishing the competitive effect. Activation of peritoneal neutrophils with heat-killed $H$. influenzae causes an increase in their ability to kill the pneumococcus, but has no effect on their ability to kill H. influenzae (Lysenko et al., 2005). The basis of this activity is not yet clear. Thus, interactions with the innate immune system can have a significant effect during competition between the pneumococcus and other microbes in the nasopharynx.

Another important microbial interaction is that of the pneumococcus and the influenza A virus. Subsequent to influenza A outbreaks, secondary pneumococcal infection is an important cause of morbidity and mortality. This heightened susceptibility to pneumococcal disease can be reproduced in animal models, allowing investigation of the mechanisms involved. While viral neuraminidase contributes to this phenomenon by exposing pneumococcal receptors (McCullers \& Bartmess, 2003; Tong et al., 2001), alterations in the immune response also seem to contribute. Prior influenza A infection in mice primes for an exaggerated inflammatory response to subsequent pneumococcal infection (van der Sluijs et al., 2004). Increased levels of IL-10 in this response likely contribute to increased susceptibility, as neutralization of this cytokine improves disease outcome (van der Sluijs et al., 2004). In vitro exposure to both influenza A and the pneumococcus results in a synergistic inflammatory response from human middle-ear epithelial cells (Tong et al., 2003). Microarray gene expression analysis of these cells following influenza A infection provides insight into the possible mechanisms behind this synergy (Tong et al., 2004). For example, it is found that tlr2 expression is upregulated by influenza A infection. This may make the cell more responsive to stimulation by pneumococcal peptidoglycan and LTA (Tong et al., 2004).

It is therefore clear that the interaction of the pneumococcus with the innate immune system is greatly influenced by the presence of other organisms such as $H$. influenzae and influenza A.

\section{Global analysis of host responses}

The advent of microarray technology allows greater insight into the host-cell response to the pneumococcus. The response of the human monocytic cell line THP-1 has been assessed by microarray analysis following exposure to S. pneumoniae and an isogenic mutant lacking pneumolysin (Rogers et al., 2003). After a three-hour exposure to the pneumococcus, expression differences were revealed in 182 host genes from the 4133 examined, illustrating the potential for large-scale expression changes induced by the pneumococcus (Rogers et al., 2003). Of these 182 genes, 142 were responsive to pneumolysin, showing the dominant nature of this virulence factor in host responses. While this study will not be comprehensive in fully documenting the host response, it illustrates the complexity of the interaction between host cells and the pneumococcus. An important future challenge will be to understand the significance of these expression changes in the disease process.

Host gene-expression changes in an infection model have been investigated in a rat model of otitis media (Chen et al., 2005). Twelve hours following pneumococcal challenge, 280 genes in the middle ear (effusion and mucosa) showed a greater than twofold change in expression compared with mock-infected controls. This represented approximately $24 \%$ of the genes examined, again showing the ability of the pneumococcus to induce large-scale changes in host gene expression. Such data allow the pneumococcal response pathways to be mapped and the identification of previously unrecognized responses. For example, it has been found 
that the transcription factor fra-1, implicated in bone proliferation, is upregulated during experimental otitis media. This provides a candidate mechanism to explain clinical features of otitis media involving the bone that are seen in both human patients and animals (Chen et al., 2005). The global response to nasopharyngeal colonization has also been investigated in a mouse model (Nelson et al., 2005). Upregulation of siderocalin, an iron-sequestering hostdefence protein, has been noted in the nasal mucosa. How the pneumococcus causes this upregulation of siderocalin is unclear, with the effect still seen in mice deficient for either TLR2 or TLR4. Interestingly, this response could not be replicated in vitro, again showing the complexity of the immune response and the value of whole-animal systems (Nelson et al., 2005). S. pneumoniae is resistant to siderocalin, and the upregulation of the latter may be advantageous to the pneumococcus by inhibiting potential competitors in the nasopharynx (Nelson et al., 2005).

In addition to the host response, global analysis of bacterial gene expression in vivo has also been studied using models of meningitis and bacteraemia (Orihuela et al., 2004). Together, these studies of host and bacterial response in vivo provide a platform to understand in molecular detail pneumococcal-host interactions from both perspectives.

\section{Concluding remarks}

Interactions between the pneumococcus and the innate immune system are multifaceted. Presented here are the recent advances in our understanding of these interactions highlighting the rapid progress in this area. Further understanding may eventually allow modulation of this interplay to aid therapy.

\section{Acknowledgements}

Work in the T. J.M. laboratory is supported by the Wellcome Trust, MRC, BBSRC, the Egyptian government and the European Union. Thanks to Dr C. E. Blue (University of Glasgow) for critical reading of the manuscript. Apologies to authors whose work could not be discussed or covered in full detail due to limitations on space.

\section{References}

Abeyta, M., Hardy, G. G. \& Yother, J. (2003). Genetic alteration of capsule type but not PspA type affects accessibility of surface-bound complement and surface antigens of Streptococcus pneumoniae. Infect Immun 71, 218-225.

Albiger, B., Sandgren, A., Katsuragi, H., Meyer-Hoffert, U., Beiter, K., Wartha, F., Hornef, M., Normark, S. \& Normark, B. H. (2005). Myeloid differentiation factor 88-dependent signalling controls bacterial growth during colonization and systemic pneumococcal disease in mice. Cell Microbiol 7, 1603-1615.

Angel, C. S., Ruzek, M. \& Hostetter, M. K. (1994). Degradation of C3 by Streptococcus pneumoniae. J Infect Dis 170, 600-608.

Arredouani, M., Yang, Z., Ning, Y., Qin, G., Soininen, R., Tryggvason, K. \& Kobzik, L. (2004). The scavenger receptor MARCO is required for lung defense against pneumococcal pneumonia and inhaled particles. J Exp Med 200, 267-272.
Bauer, S., Kirschning, C. J., Hacker, H., Redecke, V., Hausmann, S., Akira, S., Wagner, H. \& Lipford, G. B. (2001). Human TLR9 confers responsiveness to bacterial DNA via species-specific $\mathrm{CpG}$ motif recognition. Proc Natl Acad Sci U S A 98, 9237-9242.

Benton, K. A., Paton, J. C. \& Briles, D. E. (1997). The hemolytic and complement-activating properties of pneumolysin do not contribute individually to virulence in a pneumococcal bacteremia model. Microb Pathog 23, 201-209.

Bergmann, S. \& Hammerschmidt, S. (2006). Versatility of pneumococcal surface proteins. Microbiology 152, 295-303.

Branger, J., Florquin, S., Knapp, S., Leemans, J. C., Pater, J. M., Speelman, P., Golenbock, D. T. \& van der Poll, T. (2004a). LPSbinding protein-deficient mice have an impaired defense against Gram-negative but not Gram-positive pneumonia. Int Immunol 16, 1605-1611.

Branger, J., Knapp, S., Weijer, S., Leemans, J. C., Pater, J. M., Speelman, P., Florquin, S. \& van der Poll, T. (2004b). Role of Tolllike receptor 4 in Gram-positive and Gram-negative pneumonia in mice. Infect Immun 72, 788-794.

Brown, J. S., Hussell, T., Gilliland, S. M., Holden, D. W., Paton, J. C., Ehrenstein, M. R., Walport, M. J. \& Botto, M. (2002). The classical pathway is the dominant complement pathway required for innate immunity to Streptococcus pneumoniae infection in mice. Proc Natl Acad Sci U S A 99, 16969-16974.

Cauwels, A., Wan, E., Leismann, M. \& Tuomanen, E. (1997). Coexistence of CD14-dependent and independent pathways for stimulation of human monocytes by Gram-positive bacteria. Infect Immun 65, 3255-3260.

Chamaillard, M., Hashimoto, M., Horie, Y. \& 12 other authors (2003). An essential role for NOD1 in host recognition of bacterial peptidoglycan containing diaminopimelic acid. Nat Immunol 4, 702-707.

Chen, A., Li, H. S., Hebda, P. A., Zeevi, A. \& Swarts, J. D. (2005). Gene expression profiles of early pneumococcal otitis media in the rat. Int J Pediatr Otorhinolaryngol 69, 1383-1393.

Crouch, E. \& Wright, J. R. (2001). Surfactant proteins A and D and pulmonary host defense. Annu Rev Physiol 63, 521-554.

Currie, A. J., Davidson, D. J., Reid, G. S., Bharya, S., MacDonald, K. L., Devon, R. S. \& Speert, D. P. (2004). Primary immunodeficiency to pneumococcal infection due to a defect in Toll-like receptor signaling. J Pediatr 144, 512-518.

Echchannaoui, H., Frei, K., Schnell, C., Leib, S. L., Zimmerli, W. \& Landmann, R. (2002). Toll-like receptor 2-deficient mice are highly susceptible to Streptococcus pneumoniae meningitis because of reduced bacterial clearing and enhanced inflammation. J Infect Dis 186, 798-806.

Echchannaoui, H., Frei, K., Letiembre, M., Strieter, R. M., Adachi, Y. \& Landmann, R. (2005). CD14 deficiency leads to increased MIP-2 production, CXCR2 expression, neutrophil transmigration, and early death in pneumococcal infection. J Leukoc Biol 78, 705-715.

Girardin, S. E., Boneca, I. G., Carneiro, L. A. \& 12 other authors (2003). Nod1 detects a unique muropeptide from Gram-negative bacterial peptidoglycan. Science 300, 1584-1587.

Hamel, J., Charland, N., Pineau, I., Ouellet, C., Rioux, S., Martin, D. \& Brodeur, B. R. (2004). Prevention of pneumococcal disease in mice immunized with conserved surface-accessible proteins. Infect Immun 72, 2659-2670.

Han, S. H., Kim, J. H., Martin, M., Michalek, S. M. \& Nahm, M. H. (2003). Pneumococcal lipoteichoic acid (LTA) is not as potent as staphylococcal LTA in stimulating Toll-like receptor 2. Infect Immun 71, 5541-5548.

Hopkins, P. A. \& Sriskandan, S. (2005). Mammalian Toll-like receptors: to immunity and beyond. Clin Exp Immunol 140, 395-407. 
Hostetter, M. K. (2004). Interactions of Streptococcus pneumoniae with the proteins of the complement pathway. In The Pneumococcus, pp. 201-210. Edited by E. I. Tuomanen, T. J.Mitchell, D. A. Morrison \& B. G. Spratt. Washington, DC: American Society for Microbiology. Janeway, C. A., Jr \& Medzhitov, R. (2002). Innate immune recognition. Annu Rev Immunol 20, 197-216.

Jounblat, R., Kadioglu, A., Mitchell, T. J. \& Andrew, P. W. (2003). Pneumococcal behavior and host responses during bronchopneumonia are affected differently by the cytolytic and complementactivating activities of pneumolysin. Infect Immun 71, 1813-1819.

Jounblat, R., Clark, H., Eggleton, P., Hawgood, S., Andrew, P. W. \& Kadioglu, A. (2005). The role of surfactant protein D in the colonisation of the respiratory tract and onset of bacteraemia during pneumococcal pneumonia. Respir Res 6, 126.

Kadioglu, A., Gingles, N. A., Grattan, K., Kerr, A., Mitchell, T. J. \& Andrew, P. W. (2000). Host cellular immune response to pneumococcal lung infection in mice. Infect Immun 68, 492-501.

Kadioglu, A., Coward, W., Colston, M. J., Hewitt, C. R. \& Andrew, P. W. (2004). CD4-T-lymphocyte interactions with pneumolysin and pneumococci suggest a crucial protective role in the host response to pneumococcal infection. Infect Immun 72, 2689-2697.

Kang, Y. S., Kim, J. Y., Bruening, S. A. \& 7 other authors (2004). The C-type lectin SIGN-R1 mediates uptake of the capsular polysaccharide of Streptococcus pneumoniae in the marginal zone of mouse spleen. Proc Natl Acad Sci U S A 101, 215-220.

Khan, A. Q., Chen, Q., Wu, Z. Q., Paton, J. C. \& Snapper, C. M. (2005). Both innate immunity and type 1 humoral immunity to Streptococcus pneumoniae are mediated by MyD88 but differ in their relative levels of dependence on toll-like receptor 2. Infect Immun 73, 298-307.

Knapp, S., Wieland, C. W., van't Veer, C., Takeuchi, O., Akira, S., Florquin, S. \& van der Poll, T. (2004). Toll-like receptor 2 plays a role in the early inflammatory response to murine pneumococcal pneumonia but does not contribute to antibacterial defense. J Immunol 172, 3132-3138.

Koedel, U., Angele, B., Rupprecht, T., Wagner, H., Roggenkamp, A., Pfister, H. W. \& Kirschning, C. J. (2003). Toll-like receptor 2 participates in mediation of immune response in experimental pneumococcal meningitis. J Immunol 170, 438-444.

Koedel, U., Rupprecht, T., Angele, B., Heesemann, J., Wagner, H., Pfister, H. W. \& Kirschning, C. J. (2004). MyD88 is required for mounting a robust host immune response to Streptococcus pneumoniae in the CNS. Brain 127, 1437-1445.

Komai-Koma, M., Jones, L., Ogg, G. S., Xu, D. \& Liew, F. Y. (2004). TLR2 is expressed on activated T cells as a costimulatory receptor. Proc Natl Acad Sci U S A 101, 3029-3034.

Koppel, E. A., Wieland, C. W., Berg, V. C., Litjens, M., Florquin, S., Kooyk, Y. V., Poll, T. V. \& Geijtenbeek, T. B. (2005). Specific ICAM-3 grabbing nonintegrin-related 1 (SIGNR1) expressed by marginal zone macrophages is essential for defense against pulmonary Streptococcus pneumoniae infection. Eur J Immunol (in press).

Krieg, A. M. (2002). CpG motifs in bacterial DNA and their immune effects. Annu Rev Immunol 20, 709-760.

Kuronuma, K., Sano, H., Kato, K. \& 9 other authors (2004). Pulmonary surfactant protein A augments the phagocytosis of Streptococcus pneumoniae by alveolar macrophages through a casein kinase 2-dependent increase of cell surface localization of scavenger receptor A. J Biol Chem 279, 21421-21430.

Lanoue, A., Clatworthy, M. R., Smith, P., Green, S., Townsend, M. J., Jolin, H. E., Smith, K. G., Fallon, P. G. \& McKenzie, A. N. (2004). SIGN-R1 contributes to protection against lethal pneumococcal infection in mice. $J$ Exp Med 200, 1383-1393.
Lysenko, E. S., Ratner, A. J., Nelson, A. L. \& Weiser, J. N. (2005). The role of innate immune responses in the outcome of interspecies competition for colonization of mucosal surfaces. PLoS Pathog 1, el. Epub 2005 Jul 22. http://dx.doi.org/10.1371/journal.ppat.0010001

Malley, R., Henneke, P., Morse, S. C. \& 7 other authors (2003). Recognition of pneumolysin by Toll-like receptor 4 confers resistance to pneumococcal infection. Proc Natl Acad Sci U S A 100, 1966-1971.

Malley, R., Trzcinski, K., Srivastava, A., Thompson, C. M., Anderson, P. W. \& Lipsitch, M. (2005). CD4 + T cells mediate antibodyindependent acquired immunity to pneumococcal colonization. Proc Natl Acad Sci U S A 102, 4848-4853.

McCullers, J. A. \& Bartmess, K. C. (2003). Role of neuraminidase in lethal synergism between influenza virus and Streptococcus pneumoniae. J Infect Dis 187, 1000-1009.

Mitchell, T. J. (2004). Pneumolysin and other virulence proteins. In The Pneumococcus, pp. 61-74. Edited by E. I. Tuomanen, T. J. Mitchell, D. A. Morrison \& B. G. Spratt. Washington, DC: American Society for Microbiology.

Mitchell, T. J., Andrew, P. W., Saunders, F. K., Smith, A. N. \& Boulnois, G. J. (1991). Complement activation and antibody binding by pneumolysin via a region of the toxin homologous to a human acute-phase protein. Mol Microbiol 5, 1883-1888.

Mold, C., Rodic-Polic, B. \& Du Clos, T. W. (2002). Protection from Streptococcus pneumoniae infection by C-reactive protein and natural antibody requires complement but not $\mathrm{Fc}$ gamma receptors. J Immunol 168, 6375-6381.

Moscoso, M. \& Claverys, J. P. (2004). Release of DNA into the medium by competent Streptococcus pneumoniae: kinetics, mechanism and stability of the liberated DNA. Mol Microbiol 54, 783-794.

Neish, A. S., Gewirtz, A. T., Zeng, H., Young, A. N., Hobert, M. E., Karmali, V., Rao, A. S. \& Madara, J. L. (2000). Prokaryotic regulation of epithelial responses by inhibition of $\mathrm{I} \kappa \mathrm{B}-\alpha$ ubiquitination. Science 289, 1560-1563.

Nelson, A. L., Barasch, J. M., Bunte, R. M. \& Weiser, J. N. (2005). Bacterial colonization of nasal mucosa induces expression of siderocalin, an iron-sequestering component of innate immunity. Cell Microbiol 7, 1404-1417.

Opitz, B., Puschel, A., Schmeck, B., Hocke, A. C., Rosseau, S., Hammerschmidt, S., Schumann, R. R., Suttorp, N. \& Hippenstiel, S. (2004). Nucleotide-binding oligomerization domain proteins are innate immune receptors for internalized Streptococcus pneumoniae. J Biol Chem 279, 36426-36432.

Orihuela, C. J., Radin, J. N., Sublett, J. E., Gao, G., Kaushal, D. \& Tuomanen, E. I. (2004). Microarray analysis of pneumococcal gene expression during invasive disease. Infect Immun 72, 5582-5596.

Ozinsky, A., Underhill, D. M., Fontenot, J. D., Hajjar, A. M., Smith, K. D., Wilson, C. B., Schroeder, L. \& Aderem, A. (2000). The repertoire for pattern recognition of pathogens by the innate immune system is defined by cooperation between Toll-like receptors. Proc Natl Acad Sci U S A 97, 13766-13771.

Paster, B. J., Boches, S. K., Galvin, J. L., Ericson, R. E., Lau, C. N., Levanos, V. A., Sahasrabudhe, A. \& Dewhirst, F. E. (2001). Bacterial diversity in human subgingival plaque. J Bacteriol 183, 3770-3783.

Paton, J. C., Rowan-Kelly, B. \& Ferrante, A. (1984). Activation of human complement by the pneumococcal toxin pneumolysin. Infect Immun 43, 1085-1087.

Pauleau, A. L. \& Murray, P. J. (2003). Role of Nod2 in the response of macrophages to toll-like receptor agonists. Mol Cell Biol 23, 7531-7539.

Pericone, C. D., Overweg, K., Hermans, P. W. \& Weiser, J. N. (2000). Inhibitory and bactericidal effects of hydrogen peroxide production 
by Streptococcus pneumoniae on other inhabitants of the upper respiratory tract. Infect Immun 68, 3990-3997.

Philpott, D. J. \& Girardin, S. E. (2004). The role of Toll-like receptors and Nod proteins in bacterial infection. Mol Immunol 41, 1099-1108.

Picard, C., Puel, A., Bonnet, M. \& 27 other authors (2003). Pyogenic bacterial infections in humans with IRAK-4 deficiency. Science 299, 2076-2079.

Pugin, J., Schurer-Maly, C. C., Leturcq, D., Moriarty, A., Ulevitch, R. J. \& Tobias, P. S. (1993). Lipopolysaccharide activation of human endothelial and epithelial cells is mediated by lipopolysaccharidebinding protein and soluble CD14. Proc Natl Acad Sci U S A 90, 2744-2748.

Pugin, J., Heumann, I. D., Tomasz, A., Kravchenko, V. V., Akamatsu, Y., Nishijima, M., Glauser, M. P., Tobias, P. S. \& Ulevitch, R. J. (1994). CD14 is a pattern recognition receptor. Immunity 1, 509-516.

Ratner, A. J., Lysenko, E. S., Paul, M. N. \& Weiser, J. N. (2005). Synergistic proinflammatory responses induced by polymicrobial colonization of epithelial surfaces. Proc Natl Acad Sci U S A 102, 3429-3434.

Rogers, P. D., Thornton, J., Barker, K. S., McDaniel, D. O., Sacks, G. S., Swiatlo, E. \& McDaniel, L. S. (2003). Pneumolysin-dependent and -independent gene expression identified by cDNA microarray analysis of THP-1 human mononuclear cells stimulated by Streptococcus pneumoniae. Infect Immun 71, 2087-2094.

Roy, S., Knox, K., Segal, S. \& 9 other authors (2002). MBL genotype and risk of invasive pneumococcal disease: a case-control study. Lancet, 359, 1569-1573.

Schroder, N. W., Morath, S., Alexander, C., Hamann, L., Hartung, T., Zahringer, U., Gobel, U. B., Weber, J. R. \& Schumann, R. R. (2003). Lipoteichoic acid (LTA) of Streptococcus pneumoniae and Staphylococcus aureus activates immune cells via Toll-like receptor (TLR)-2, lipopolysaccharide-binding protein (LBP), and CD14, whereas TLR-4 and MD-2 are not involved. J Biol Chem 278, 15587-15594.

Shakhnovich, E. A., King, S. J. \& Weiser, J. N. (2002). Neuraminidase expressed by Streptococcus pneumoniae desialylates the lipopolysaccharide of Neisseria meningitidis and Haemophilus influenzae: a paradigm for interbacterial competition among pathogens of the human respiratory tract. Infect Immun 70, 7161-7164.

Srivastava, A., Henneke, P., Visintin, A. \& 7 other authors (2005). The apoptotic response to pneumolysin is Toll-like receptor 4 dependent and protects against pneumococcal disease. Infect Immun 73, 6479-6487.

Szalai, A. J., Agrawal, A., Greenhough, T. J. \& Volanakis, J. E. (1997). C-reactive protein: structural biology, gene expression, and host defense function. Immunol Res 16, 127-136.

Takeda, K., Kaisho, T. \& Akira, S. (2003). Toll-like receptors. Annu Rev Immunol 21, 335-376.

Tong, H. H., Weiser, J. N., James, M. A. \& DeMaria, T. F. (2001). Effect of influenza A virus infection on nasopharyngeal colonization and otitis media induced by transparent or opaque phenotype variants of Streptococcus pneumoniae in the chinchilla model. Infect Immun 69, 602-606.

Tong, H. H., Long, J. P., Shannon, P. A. \& DeMaria, T. F. (2003). Expression of cytokine and chemokine genes by human middle ear epithelial cells induced by influenza A virus and Streptococcus pneumoniae opacity variants. Infect Immun 71, 4289-4296.

Tong, H. H., Long, J. P., Li, D. \& DeMaria, T. F. (2004). Alteration of gene expression in human middle ear epithelial cells induced by influenza A virus and its implication for the pathogenesis of otitis media. Microb Pathog 37, 193-204.

Travassos, L. H., Girardin, S. E., Philpott, D. J., Blanot, D., Nahori, M. A., Werts, C. \& Boneca, I. G. (2004). Toll-like receptor 2dependent bacterial sensing does not occur via peptidoglycan recognition. EMBO Rep 5, 1000-1006.

Um, S. H., Son, E. W., Kim, B. O., Moon, E. Y., Rhee, D. K. \& Pyo, S. (2000). Activation of murine peritoneal macrophages by Streptococcus pneumoniae type II capsular polysaccharide: involvement of CD14dependent pathway. Scand J Immunol 52, 39-45.

van der Sluijs, K. F., van Elden, L. J., Nijhuis, M. \& 7 other authors (2004). IL-10 is an important mediator of the enhanced susceptibility to pneumococcal pneumonia after influenza infection. J Immunol 172, 7603-7609.

van Rossum, A. M., Lysenko, E. S. \& Weiser, J. N. (2005). Host and bacterial factors contributing to the clearance of colonization by Streptococcus pneumoniae in a murine model. Infect Immun 73, 7718-7726.

Walport, M. J. (2001). Complement. First of two parts. N Engl J Med 344, 1058-1066.

Weber, J. R., Freyer, D., Alexander, C., Schroder, N. W., Reiss, A., Kuster, C., Pfeil, D., Tuomanen, E. I. \& Schumann, R. R. (2003). Recognition of pneumococcal peptidoglycan: an expanded, pivotal role for LPS binding protein. Immunity 19, 269-279.

Whitsett, J. A. (2005). Surfactant proteins in innate host defense of the lung. Biol Neonate 88, 175-180.

Yamamoto, M., Takeda, K. \& Akira, S. (2004). TIR domaincontaining adaptors define the specificity of TLR signaling. Mol Immunol 40, 861-868.

Yoshimura, A., Lien, E., Ingalls, R. R., Tuomanen, E., Dziarski, R. \& Golenbock, D. (1999). Cutting edge: recognition of Gram-positive bacterial cell wall components by the innate immune system occurs via Toll-like receptor 2. J Immunol 163, 1-5.

Yuste, J., Botto, M., Paton, J. C., Holden, D. W. \& Brown, J. S. (2005). Additive inhibition of complement deposition by pneumolysin and PspA facilitates Streptococcus pneumoniae septicemia. J Immunol 175, 1813-1819.

Zhang, Y., Masi, A. W., Barniak, V., Mountzouros, K., Hostetter, M. K. \& Green, B. A. (2001). Recombinant PhpA protein, a unique histidine motif-containing protein from Streptococcus pneumoniae, protects mice against intranasal pneumococcal challenge. Infect Immun 69, 3827-3836. 